\title{
The three Cs of intensity: understanding rail-based urban assemblage in Brooklyn
}

\author{
M. Vujic \\ Faculty of Architecture, Building and Planning, \\ The University of Melbourne, Melbourne School of Design, Australia
}

\begin{abstract}
Transit-oriented urban intensification is proposed to be the most fundamental planning approach for a sustainable city. The key notion of urban intensity remains vague referring to the integration of land-use, transport and density. Limited research at local scale, reduction to urban form and the lack of a clear conception of intensity has led to inconsistencies in the discourse of transit-orientation. The Brooklyn case study is presented as a laboratory for exploring urban intensity of this rail-based assemblage. The selected study area is mid-rise, compact mix of housing, retail, offices, industry and amenities. The analysis is based on assemblage thinking: place is conceived as a synergy of people, dwellings, functions, densities, flows and practices. It is here proposed that the three complementary Cs: concentration, connectedness and co-functioning mediate urban intensity. Concentration resonates with building heights, site coverage, dwelling densities, co-functioning with functional, formal and social mix, and connectivity with access, movement networks. Urban intensity emerges from the interaction, links and adaptations of the three $\mathrm{Cs}$, and is manifested in flows of people, transport, information and goods throughout the city. This paper explores ways in which urban intensity emerges in the Brooklyn assemblage. This comprehensive multi-scalar understanding of urban intensification contributes to sustainable urban practices.

Keywords: urban intensity, place, assemblage theory, transit-oriented urban design, urban morphology.
\end{abstract}

\section{Introduction}

Transit-oriented urban intensification is a form of development that has emerged as a response to the global environmental awareness. It concentrates people, 
functional mix, and activities within walking distances in transit-based urban centre(s) [1-3]. Urban intensification aims to meet the imperatives for sustainable cities and regions by providing a compact urban morphology oriented to public transport [4-6]. The inconsistency related to such development is twofold: there is a lack of attention to local scale implementation [7], and a tendency in urban studies to segregate formal and social aspect in cities [8-10]. For Williams et al. [7] the proposed compact 'models' aim for sustainable urban form at regional and metropolitan scale. However, social equity and choice are reflected on the scale of neighbourhood amenities and services, pedestrian and public transport accessibility and cultural diversity; the lack of these is an unsustainable scenario. Hillier [8] argues on the issue of 'compartmentalisation' to economic and social affairs dealt by urban planning, and spatial and physical aspects of a city tackled by urban design. He maintains that the city's 'sociality' and 'spatiality' are complementary aspects mediated through movement [11].

This paper aims to reconcile the ambiguities in transit-oriented urban intensification. It aims to rethink intensification that has shifted away from the notion of place intensity that underpins it. The paper explores ways in which the alliance of three Cs: concentration, connectedness and co-functioning of place mediates urban intensity. It has been shown that the place intensity emerges from the links and complementarity between urban morphology, activities and processes.

\section{Urban intensity and assemblage thinking}

The theory on transit-oriented development exhibits conflicted notions of density and intensity. There is a key difference between the extensive, formal notion of density, and urban intensity as the way in which the city is used. For Dovey and Pafka [12], intensity is "the experience of intensive encounter in public space that may or may not emerge under conditions of density. [...it is] more than the sum of parts." The argument here is that high densities per se are not a prerequisite for lively and intensively used public space.

Place intensity is in urban environments represented as pedestrian volume, encounter, and activity in public space. Pedestrian volume denotes the density of active users in open space, attracted by the diverse functions in urban environments. It is also linked with the idea of 'user intensity' [13]. This intensity is conceived as the share of residents and visitors in a place: "[w]orkplaces, tourists and visitors of different kinds of amenities; all contribute differently to the user intensity of network and other public spaces" [13]. Pedestrian volume depends on different local and bigger scale qualities of a place; it reflects the level of synergy between land-use, floor-space, but also transport modes and their accessibility. Space syntax theory also detects the pattern of 'spatial configuration': there is a direct correlation between the concentration of pedestrian flows and density of land-use mix along the global city streets [8]. Urban intensity is here referred to as a socio-spatial phenomenon that emerges from the interconnections and synergies within the assemblage of concentration, co-functioning and connectivity; it is genuinely multi-scalar. 
This paper reflects on Deleuzian philosophy where place denotes the alliance between urban morphology and flows. The main concept of assemblage theory is the part-to-whole relationship. Deleuze and Guattari [14] argue that an assemblage is a multiplicity of parts, not a mere collection. DeLanda $[15,16]$ interprets the assemblage more clearly. For him, assemblages are "wholes whose properties emerge from the interactions between parts" [15]. For Dovey [17], assemblage is dynamic; its parts are growing, developing and dying; buildings are built, renovated and demolished. He illustrates the complexity and dynamism of the street assemblage - its character is defined in the way built-form, land use, networks, people, activities and flows interact. Every assemblage is always multiscalar; it as always linked to micro and macro [14, 17]. An assemblage of a street is a liaison of micro assemblages of people, sidewalks, activities, but it also forms a macro assemblage of a district or a city.

\section{Brooklyn case analysis}

The focus of this multi-scale analysis is the Bergen subway station. It is located at the intersection of Flatbush Avenue and Bergen Street, twenty minute walk from Brooklyn Downtown, and ten kilometres away from Manhattan Midtown. Densities, land-use mix and transit-orientation of Brooklyn case reflect its capacity to foster the understanding of transit-based assemblages. The site is approached as a laboratory for exploring links between urban intensity and transit-orientation.
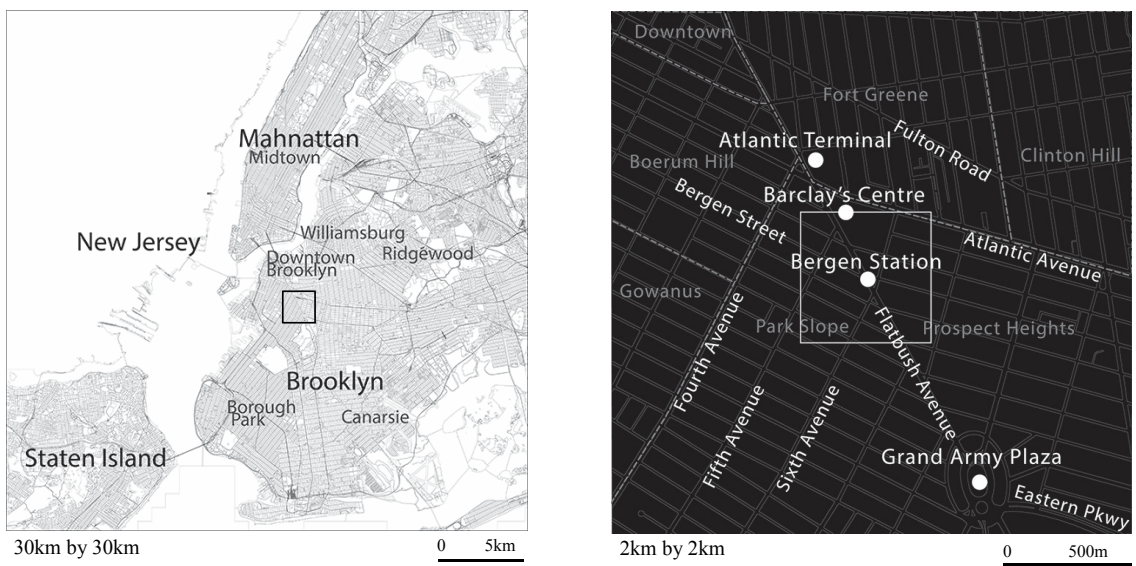

Figure 1: Brooklyn case study; $30 \mathrm{~km}$ by $30 \mathrm{~km}$ (left) and $2 \mathrm{~km}$ by $2 \mathrm{~km}$ (right).

\subsection{Multi-scale analysis and morphological mapping}

Brooklyn rail-based assemblage is studied across multiple scales, through space syntax and morphological mapping. Multi-scale analysis reflects the assemblage theory. It also enables a comprehensive analysis of concentration, co-functioning and place connectivity. The analysis is conducted at the commuting distance scale 
of $30 \times 30 \mathrm{~km}$, cycling distance scale of $2 \times 2 \mathrm{~km}$ (400 hectares) and walking distance scale of 500x500m (25 ha). They all refer to square-shaped frame, centred on the selected rail stations. Morphological mapping is a second complementary method based on fieldwork data collection. There is a distinction between tracing the current site condition and morphological mapping; mapping "lies in neither reproduction nor imposition but rather in uncovering realities previously unseen or unimagined" [18].

\subsection{Concentration}

According to Pont and Haupt [19], density can be measured in different ways. The most common ones are densities of people, dwelling units or building mass per given area. The authors argue that the ambiguous values of density often result from the way area boundary is defined. On a metropolitan scale, this means that the bigger the selected area is the more of the non-built zones it will include (water, roads, railways, green areas), and density values will decrease. On an urban block scale, density quotes depend on the defined boundary - whether or not the roads and open spaces are included in the area. Pont and Haupt [19] criticize the lack of convention in urban design and planning that would reduce the inconsistencies in density calculation.

In order to avoid the confusions of a single density measure, Pont and Haupt [19] develop a 'multivariable definition of density' or 'spacemate' that incorporates an assemblage of interlinked values of gross floor area, base land area, coverage and network length. This approach spans across the different expressions of building densities. It is a comprehensive way to describe urban morphology in terms of the concentration of built form, networks, open space, building height. Spacemate is critical in transit-oriented urbanism where density plays a key role for viability of public transport and environmental performance. The concept of network density is one of the spacemate variables that resonate with the Jacobs' [20] idea of permeability, or 'short blocks' [12]. This is also a cross-reference between the themes of concentration and connectivity in urban design.

Multivariable density analysis on a 25ha scale shows a diversity of grain size, building heights and dwelling densities. Dwelling density is shown to be independent of the lot size and building height - there is evidence for both large and small grain having more than 250 dwellings per hectare (figure 2). This is an indicator of the genuine mix of the dwelling sizes, which is a prerequisite for diverse social structure of this place.

Floor area ratio (FAR), ground space ratio or coverage (GSR) and open space ratio or spaciousness (OSR) are density variables relative to building height, footprint and grain size. The overlap of these indicates that 'density' of the site cannot be reduced to any of the three measures of density. In this sense, it is shown that building height of four stories (Barclays centre) does not necessarily imply high FAR as the coverage on a block level is low. They each add up to understanding urban morphology. The spaciousness is also a key indicator of density showing the 'pressure on non-built space' [19]. The intersection of built form density (FAR, GSI and OSR) with dwelling density is linked to the 

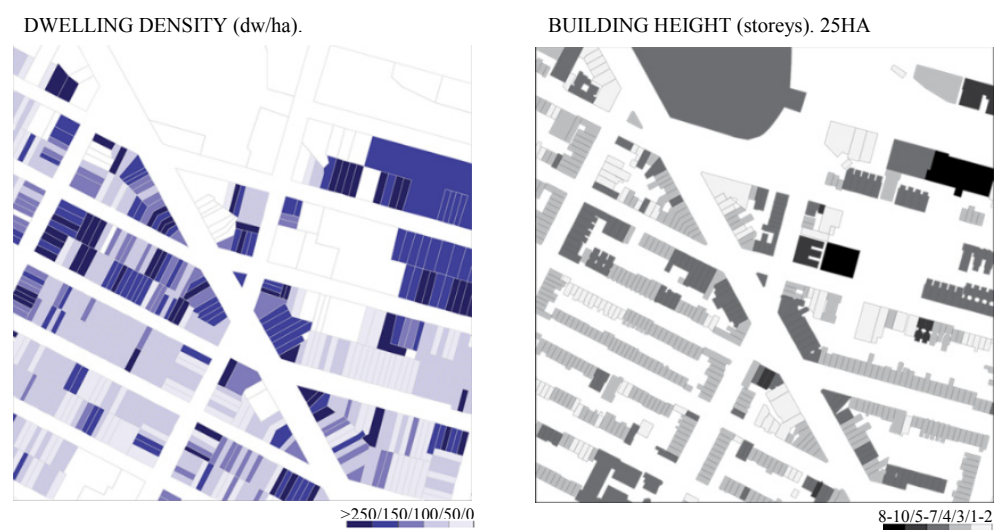

Figure 2: Density variables in Brooklyn case study; $500 \mathrm{~m}$ by $500 \mathrm{~m}$.

performative aspects of density [19]. This density performance indicates the functional mix, connectivity and common open space between the buildings [19]. This reflects not just the spatial layout, but also the way in which the place operates in social terms.

\subsection{Co-functioning}

Land-use diversity is one of the most intensively used concepts in urban design and planning. It has been introduced as early post-modern critique of functional zoning. This land-use segregation was contested for its negative socioenvironmental impact [20]. Residential districts detached from employment and services are energy extensive and dependent on cars. This lifestyle then affects metropolitan movement patterns and development where major investments associate to outward urban growth and road infrastructure. There is also the issue of social equity. The non-drivers, too old, too young or the ones that cannot afford to drive, have poor access to jobs and amenities. The increased global awareness of the impact of land-use zoning results in the imperatives for the functional mix.

The mix of uses involves co-functioning of residential functions that provide local flows, and retail, leisure and job functions which bring external uses to an urban district. Such synergies make street vibrant, safe and serve the needs of residents while retail benefits both from residents and visitors in the area [20]. There is a strong resonance between Jacobs' [20] 'diversity of land-uses' and the notion of 'spatial configuration' [9, 10]. Space syntax demonstrates the coexistence of functional mix and the intensity of flows. In this way, local streets are usually of low pedestrian activity, whereas main pedestrian streets are in symbiosis with diverse land-uses.

Functional mix has been mapped adapting the land-use triangle by van Nes et al. [21]. They have determined primary uses of 'working', 'amenities' and 'housing' and have displayed them in a triangle of primary colours. Uses are here linked to flows they induce. Purely 'work'-related functions induce high intensity 
of flows in morning and afternoon peak, whereas 'visit' uses attract flows throughout the day contributing continuously to street-life. The buildings or uses that entail the mix of any two are found in the mix or the main colours, and mix of all three becomes grey.

The 400ha area of the Bergen case illustrates the patterns of land-use distribution (figure 3). Land-use mix tends to line up along the main transversal route of Flatbush Avenue, but also along the secondary streets that connect to it. The barrier of the ground-level railway along the Atlantic Avenue has had an influence on the network permeability. This has inhibited the emergence of mixeduse corridors that are often dependent upon the intensive flows [11]. Emancipated from the low-permeability impact zone, the mixed use corridors again emerge to the north of this barrier. The Atlantic Ave activity corridor is discontinuous in area affected arguably by the lack of flows (the vast parking triangle south to the Fulton Street).
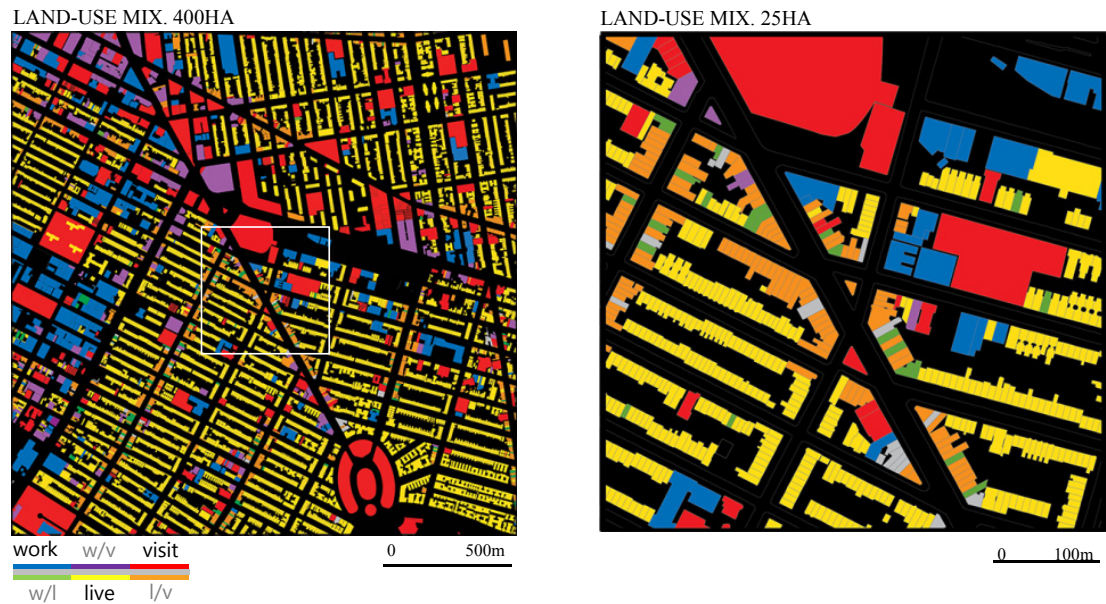

Figure 3: Land-use mix; $2 \mathrm{~km}$ by $2 \mathrm{~km}$ (left) and $500 \mathrm{~m}$ by $500 \mathrm{~m}$ (right).

The north-west part of the 400ha frame is directed towards the Brooklyn Downtown and demonstrates the concentration and mix of 'work'- and 'visit'related uses. Comparatively across the site, these are also associated with the larger lot areas. Western part of the site clusters the 'work'-related uses, mostly warehouses, repair-shops or small industries. The prevalent larger grain size, as well as the high level of compactness, is allowed by the function itself. The residential tissue between the shopping corridors and 'work'- and 'visit'-based areas is predominantly linked with the row townhouse morphology that varies between two and four stories. The only exception is the cluster of large grain residential buildings above six-stories high that gravitate towards the Grand Army plaza. 
The 25ha frame is focused at Bergen subway station. The confluence of two mixed use corridors is the intersection of Flatbush and Fifth Avenue. The cofunctioning of uses is represented predominantly in the mix of ground-level retail, amenities, and firms, with housing on the upper floors. Mixed-use pattern 'bleeds' from the two main corridors into the contiguous streets. This reflects the synergy between the pattern of functions and key activity lines in of the network. 'Visit'based functions are mostly located within the vertical mix with residences; the only exceptions are the large grain Barclays Centre to the north and the sports fields to the west. Cropping the residential uses out of the land-use map implies that the small grain almost entirely disappears. Larger lot areas and higher values of building heights are related to offices, industry and schools. Co-functioning also reflects the mix of building types. Residential row houses with the elevated ground floor exist within a range of building heights and footprint size. As the height increases from three to four levels, the building form adjusts according to the need for natural light. The lateral sides of the building volumes get vertical extrusions that allow for greater depth of the base.

\subsection{Connectivity}

Place connectivity is linked to movement and the way it is mediated through networks, accessibility and transport modes. Connectivity is multi-scalar and temporal. It accounts both for local connectivity and short travel times, and global one related to longer trips.

A useful approach to connectivity is denoted in space syntax that tackles various levels and aspects of connectivity 'to-movement' or 'integration' and 'through-movement' or 'choice' [22]. 'Integration' refers to the average linear 'depth' - mean number of lines between every individual one and all the other ones in the selected network. More integrated streets carry out more movement, so the level of integration represents a direct link between the spatial structure and flows through it. Those two components of movement link origin and destination of any trip. In space syntax, they can be analysed metrically ('shortest path' analysis), geometrically ('least angle' analysis) and topologically ('fewest turns' analysis). Space syntax enables the setting of the scale of integration. One can calculate 'local integration' by determining the integration of each street up to three streets away, or 'global integration' by determining the integration in relation to all the streets [8]. These analyses determine the capacity of the network to mediate urban morphology and social life through movement.

Accessibility isochrones represent the distance one can travel from a focal train station on different modes for 20 and 30 minutes. Car and public transport accessibility catchments are mapped for morning peak and evening. The car catchments include the average of five minutes delay for parking. Public transport isochrones contain half of the frequency in the total time to cover the average waiting period and the walking time. The value of this method is in the simulation of actual movement patterns in urban environments denoted in the waiting and parking time, headway, peak-hours congestion and lower PT frequencies in the evenings. 
The $30 \mathrm{~km}$ by $30 \mathrm{~km}$ scale analysis (figure 4 ) shows the relationship between areas accessible by car and public transport (PT). Morning peak isochrones demonstrate that the public transport strongly competes with cars for the thirty minutes travel time.

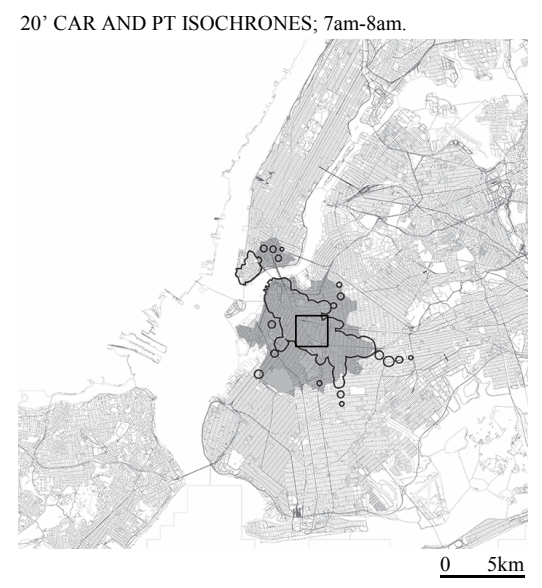

20' CAR AND PT ISOCHRONES; 9pm-11pm.

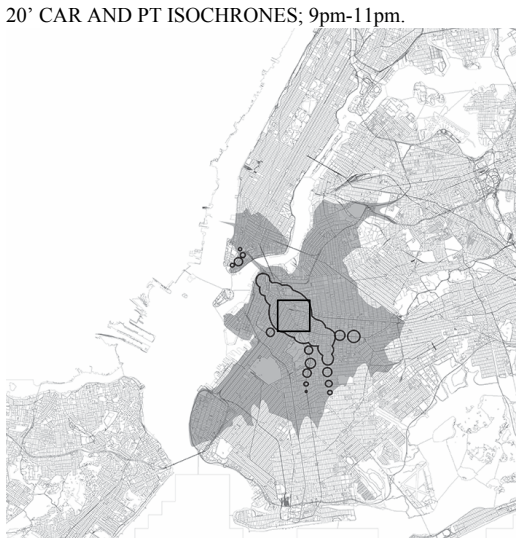

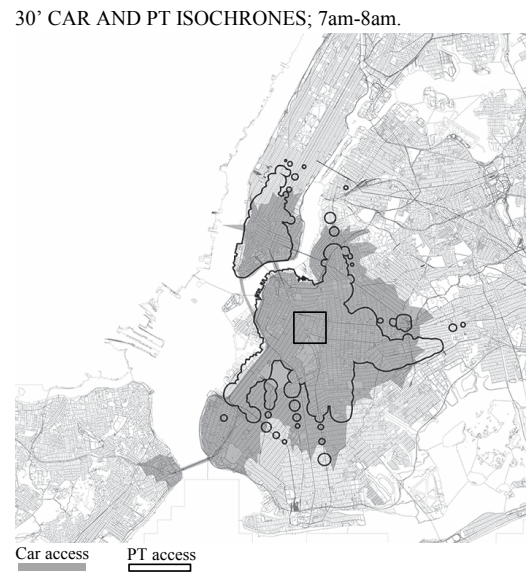

30' CAR AND PT ISOCHRONES; 9pm-11pm.

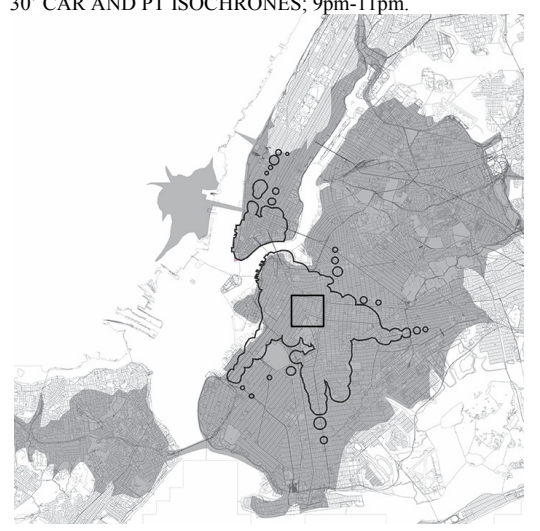

Figure 4: Isochrones of car and public transport accessibility; $30 \mathrm{~km}$ by $30 \mathrm{~km}$.

Public transport network provides access in all directions except for the southeast and northeast (Ridgewood and Canarsie). The twenty minute PT isochrones are mostly focused along the Flatbush Avenue and Eastern Parkway corridors (subway lines 2, 3, 4, 5, B, Q). The small ratio between cars and public transport in morning peak is arguably the result of road congestion and high PT frequency. The comparison between morning and evening accessibility for PT implies the similar coverage in major directions; access is in the evening reduced towards Borough Park (southwest), Williamsburg and Ridgewood (northeast), and Canarsie (southeast). The evening also cancels road congestion, which allows cars to reach extensive areas in Brooklyn, but also southern tip of 
Manhattan up to Midtown; then area serviced by the Staten Island Expressway, and even to Jersey City. Despite the relatively consistent PT coverage area, the evening analysis implies an outstanding advantage of car-based flows.

The 400ha analysis represents the distribution of subway, rail and bus lines. Network overlaps take place at the Atlantic station, the major PT node, but also towards the Brooklyn Downtown to the north-west of the site. The intensity of the network intersections tends to spiral down as it moves further from the Downtown area. The lines oriented towards south-west or east meet the ones aligned with Flatbush Avenue and Fulton Street. Reflecting back to the $30 \mathrm{~km}$ by $30 \mathrm{~km}$ scale it is evident that the access catchment area fattens along the main collectors bundles of Flatbush and Fulton Street. On the other hand, the lack of lateral links (as well as the distance from the focal site) shrinks down the serviceable areas along the radial lines of the network.

Space syntax analysis conducted at 400ha scale measures topological 'integration' and angular 'choice' values of the place. The integration value is calculated for the radius ' $n$ ' - global network integration. The angular 'choice' determines the radius of $800 \mathrm{~m}$, denoting the choices within the network from Bergen station. This radius corresponds to ten minutes of walking or five minutes of biking. The overlay of major activity portals (in red, figure 5: multiunit housing, parking, shopping centres) complements the analysis.

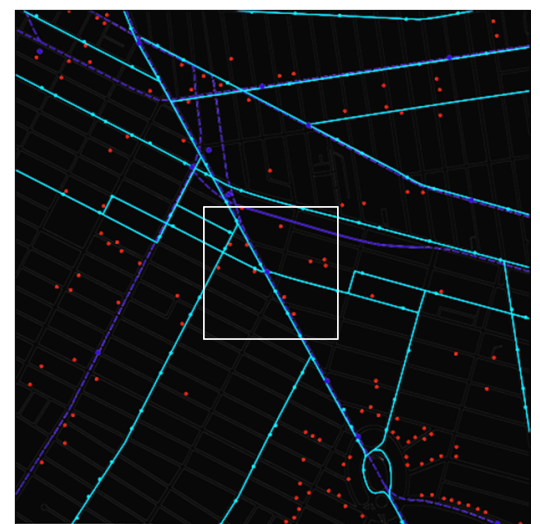

rail subway bus subway station / bus stop / other portals

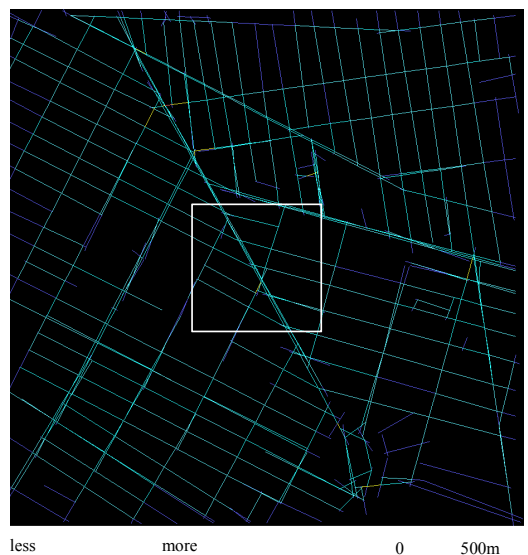

less

Figure 5: Networks, portals and space syntax global integration; $2 \mathrm{~km}$ by $2 \mathrm{~km}$.

Global topological integration denotes the highest integration values (red and orange) for Flatbush and Fulton road. There is also a strong resonance between the highly integrated lines and public transport network. The measure of choice here reflects walkability for ten minutes. It shows that the highest value of choice associates with major PT routes, then areas with intensive overlap and intersection of PT network. The impact of the ground-level rail barrier that has affected landuse co-functioning is also evident in the low value of choice (dark blue). Interestingly, the area of Grand Army plaza to the south-east has low levels of 
integration and choice, despite the high density of activity portals which here refer to multi-unit housing (figure 5). High levels of integration and choice are proportional to mixed-use corridors. Predominantly 'work'-related area to the west and mono-functional residential areas are characterized with low integration and choice values.

The 25ha network mapping implies the similar links to space syntax: high topological integration and an angular choice are focused along the strips of mixed use which are also the main corridors of public transport. The density overlay demonstrates that dwelling density is directly related to high integration values if the residential use co-exists in a mix of amenities and offices. In this sense, highly integrated and mixed-use Fifth and Flatbush Ave also have the high density of dwellings. However, the high dwelling density in areas that are mono-functional corresponds to the low integration value.

\section{Urban intensity: Brooklyn assemblage}

Pedestrian flows and shopping strips mediate between the urban morphology and intensity. This street-life is measured in the morning peak from 7am to 9am, at noon from $12 \mathrm{pm}$ to $2 \mathrm{pm}$, and in the afternoon from $5 \mathrm{pm}$ to $6 \mathrm{pm}$ (figure 6 ). Pedestrians were counted for five minutes across the 25 ha study area for every sidewalk of the street, 5-10 metres before the intersections. Shopping strips delineate the retail frontages. The layout of shopping interfaces indicates high capacity for intensive pedestrian flows.
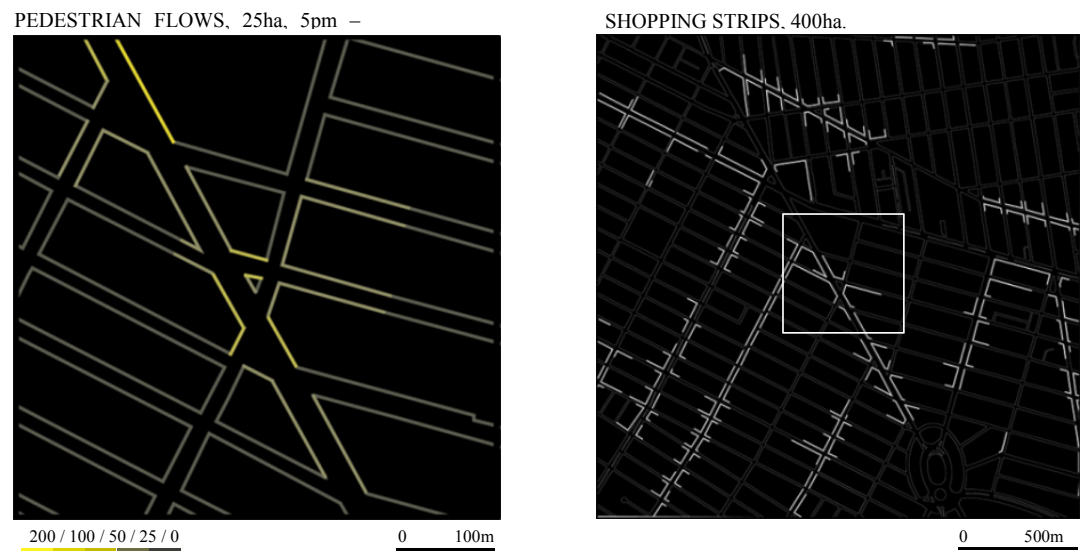

Figure 6: Urban intensity; $500 \mathrm{~m}$ by $500 \mathrm{~m}$ (left) and $2 \mathrm{~km}$ by $2 \mathrm{~km}$ (right).

Intensity analysis renders highest pedestrian volumes aligned along the Flatbush Ave. High values are also accumulated around the Bergen station in all directions. Superimposed over the maps of three Cs, street-life concurs with shopping strips and mixed-use. Pedestrian flows are also tied-up with spatial integration and choice. Lowest pedestrian intensity is affined to purely residential 
areas, as well as along the railway interfaces. The 400ha scale shopping strips highlight the same movement intensive lines produced by space syntax, and also align with mix-use corridors (figure 6). The zones deficient of retail fronts are the ones of poor integration and lower values of density.

It is manifested that the analytic themes of concentration, co-functioning and connectivity resonate with the notion of urban intensity. Multivariable concept of density is linked to 'urban performance' or urbanity; functional mix coded to reflect potential flows, corresponds to the measured pedestrian volumes. Shopping strips are recognized as morphological indicators of urban intensity and are based on the distribution of "visit' land-use.

Connectivity is an aspect of urban morphology that represents the level of network effectiveness in channelling flows. In space syntax, connectivity reflects flows and mediates between morphology and social performance. Integration and choice measures are shown consistent with the urban intensity implicit in morphological maps of densities, mix, shopping strips, networks and access.

\section{Discussion and conclusion}

The process of understanding the way in which a rail-based assemblage works has gone through many steps of analysis. This case study was tackled across the $30 \mathrm{~km}-, 2 \mathrm{~km}-$ and 500m-scale through mapping. Individual morphological maps of either of the three Cs have revealed certain properties of Brooklyn case. However, the analyses resisted conclusions based on any of the single layer of concentration, co-functioning or connectivity. Linear analytic progression has shown to be inconsistent. On the other hand, cross-comparison of the information within each of the three Cs as well as laterally across the Cs has enabled the understanding of the underlying processes in this place.

It has firstly been shown that density measures of building height, floor area ratio, open space ratio, coverage and dwelling density are inconsistent. The analyses demonstrated that some patterns linking density measures might exist. It becomes crucial to include the other layers of information to unravel the exposed intricacies. For example, dwelling density is a measure that associates functional with formal aspect of density. In urban intensification theory, dwelling densities are critical for viable public transport and safety. The Brooklyn case shows that high values of dwellings per hectare do not necessarily imply urban morphology associated with intensive street-life. Overlapping different aspects of concentration with land-uses sheds additional light to urban intensity of this place. The most intensively used streets are the ones with a mix of amenities, jobs and housing, as well as the formal mix of different grain sizes and different densities. Contrary to common fears in community and developers' discourses of intensification, highest buildings show to be irrelevant for urban intensity. Cofunctioning of uses vertically (within a building), as well as horizontally (along a street) resonates with the highest values of pedestrian flows. An additional overlay of connectivity complements the understanding of the emergent properties of this rail-based assemblage. Space syntax integration and choice graph strongly correlates to actively used streets. However, space syntax itself is not an absolute 
indicator of intensity. Its asynchrony with the street-life intensity is often the case of poor functional and/or formal mix. Accessibility isochrones have shown that the directions with the highest values of access on a city scale correspond to the streets with high intensity, rich mix of forms and uses on a local scale. Public transport networks and nodes contribute strongly to urban morphology and the way it performs. However, these are again not a 'sufficient' condition for urban intensity. Only the alliance of concentration, co-functioning and connectivity fosters the understanding of flows, form and processes in this urban place.

This paper presents place as a liaison of form, functions, connections, practices and people; it is irreducible. The paper stresses the importance of cross-scale approach to urban intensity: on street-, neighbourhood-, and city-scale. Intensity is here shown to be proportional to effective public transport, mix of amenities and housing, walkability, densities; all strongly linked to urban sustainability. It is thus an imperative of urban intensification to develop sensitivity to synergies that make urban intensity. Intensity as a multi-scalar assemblage of concentration, cofunctioning and connectivity, represents a conceptual lens for a comprehensive framework of urban sustainability.

\section{Acknowledgements}

This paper is part of the on-going $\mathrm{PhD}$ thesis 'Transit-based urban assemblages: Designing the intensive low-carbon city' at the University of Melbourne that explores three international case studies - in Brooklyn, NY; Jiyugaoka, Tokyo; Södermalm, Stockholm. The findings will be applied to propose urban design strategies for intensification of the low-density car-dependent case study in Footscray, Melbourne. I thank Kim Dovey for supervision of this research. I also thank my research supervisors on the 'Intensifying Places' project: Kim Dovey, Lucy Pike and Ian Woodcock for developing the 'isochrones' method used for mapping transport accessibility.

\section{References}

[1] Newman, P.W.G., \& Kenworthy, J.R., Sustainability and Cities: Overcoming Automobile Dependence, Island Press: Washington, DC, 1998.

[2] Newman, P.W.G., \& Kenworthy, J.R., Urban design to reduce automobile dependence. Opolis, UC Riverside, 2(1), pp. 35-52, 2006.

[3] Curtis, C., Planning for sustainable accessibility: The implementation challenge. Transport Policy 15(1), pp. 104-112, 2008.

[4] Breheny, M.J., Sustainable Development and Urban Form, European Research in Regional Science, Pion: London, 1992.

[5] Owens, S.E., Energy, Planning, and Urban Form, Pion: London, 1986.

[6] Minnery, J.R., Urban Form and Development Strategies: Equity, Environmental and Economic Implications, Australian Govt. Pub. Service: Canberra, 1992.

[7] Williams, K., Burton, E. \& Jenks, M., Achieving the compact city through intensification: An acceptable option? (part 2). The Compact City: A 
Sustainable Urban Form?, ed. M. Jenks, E. Burton \& K. Williams, E \& FN Spon: London, Melbourne, pp. 71-83, 1996.

[8] Hillier, B., Space Is the Machine: A Configurational Theory of Architecture, Cambridge University Press: Cambridge, New York, p. 149, 1996.

[9] Vaughan, L., The spatial syntax of urban segregation. Progress in Planning, 67(3), p. 205-294, 2007.

[10] Hillier, B., \& Hanson, J., The Social Logic of Space, Cambridge University Press: Cambridge, New York, 1984.

[11] Hillier, B., Space and spatiality: What the built environment needs from social theory. Building Research \& Information, 36(3), pp. 216-230, 2008.

[12] Dovey, K., \& Pafka, E., The urban density assemblage: Modelling multiple measures. Urban Design International 19(1), pp. 66-76, 2014.

[13] Pont, M.B., \& Haupt, P., Spacematrix: Space, Density and Urban Form, NAI: Rotterdam, pp. 228-230, 2010.

[14] Deleuze, G., \& Guattari, F., A Thousand Plateaus: Capitalism and Schizophrenia, University of Minnesota Press: Minneapolis, 1987.

[15] DeLanda, M., A New Philosophy of Society: Assemblage Theory and Social Complexity, Continuum: London, New York, pp. 1-46, 2006.

[16] DeLanda, M., Philosophy and Simulation: The Emergence of Synthetic Reason, Bloomsbury Academic: New York, pp. 184-203, 2011.

[17] Dovey, K., Becoming Places: Urbanism/Architecture/Identity/Power, Routledge: London, New York, pp. 13-30, 2010.

[18] Corner, J., The Agency of Mapping. Mappings, ed. D. Cosgrove, Reaktion: London, pp. 213-252, 1999.

[19] Pont, M.B., \& Haupt, P., Spacematrix: Space, Density and Urban Form, NAI: Rotterdam, pp. 98-100, 2010.

[20] Jacobs, J., The Death and Life of Great American Cities, Random House: New York, 1961.

[21] van Nes, A., Pont, M.B., \& Mashhoodi, B., Combination of space syntax with spacematrix and the mixed use index: Symposium, Santiago, PUC, pp. 1-29, 2012.

[22] Hillier, B., Studying cities to learn about minds: Some possible implications of space syntax for spatial cognition. Environment \& Planning B: Planning \& Design. 39(1), pp. 12-32, 2012. 